\title{
Alfabetização e letramento: um estudo de caso com um aprendente de escola pública
}

O termo letramento pode ser considerado atual no campo da educação brasileira, usado inicialmente com uma abordagem antropológica, sendo que as práticas de leitura e escrita só começaram a ser pesquisadas a partir da década de 70 . É na infância que se faz necessária a aquisição da leitura, principalmente nas séries iniciais do ensino fundamental, já que a partir de uma base bem estruturada, o aprendente irá se desenvolver de forma mais integral. Através da leitura, pode-se ter uma compreensão eficaz do mundo em que se estar inserida, sendo parte fundamental para a formação de um indivíduo no mundo atual. 0 estudo de caso apresentado neste artigo trata de um aprendente que do ponto de vista afetivo demonstra condições inadequadas de relacionamento: o caso vem ilustrar a problemática nas relações familiares observado nas provas projetivas onde os vínculos são negativos. No cognitivo demonstra falta de envolvimento com o objeto de aprendizagem e com o conhecimento do transmissor. Seu nível pedagógico e criativo está abaixo de sua escolaridade e de sua faixa etária, encontra-se no período silábico sem valor sonoro, pois ele tem consciência que existe relação entre a fala e a escrita, porém não identifica os sons das letras, utilizando os símbolos gráficos de forma aleatória sem corresponder à escrita convencional. Mesmo com os resultados e as conclusões obtidas, torna-se importante realizar outros estudos em seu conjunto no tocante da alfabetização e letramento para que se possa contribuir ainda mais com a comunidade científica.

Palavras-chave: Alfabetização; Letramento; Dificuldades de Aprendizagem.

\section{Literacy and literacy: a case study with a public school student}

\begin{abstract}
The term literacy can be considered current in the field of Brazilian education, initially used with an anthropological approach, and reading and writing practices only began to be researched from the 70 s onwards. It is in childhood that it is necessary to acquire reading, especially in the early grades of elementary school, since from a well-structured basis, the learner will develop more integrally. Through reading you can have an effective understanding of the world in which you are inserted, being a fundamental part for the formation of an individual in the current world. The case study presented in this article deals with a learner who, from an affective point of view, demonstrates inadequate relationship conditions: the case illustrates the problem in family relationships observed in projective tests where bonds are negative. In the cognitive, it shows a lack of involvement with the learning object and with the knowledge of the transmitter. His pedagogical and creative level is below his schooling and his age range, he is in the syllabic period with no sound value, as he is aware that there is a relationship between speech and writing, but does not identify the sounds of letters, graphic symbols at random without corresponding to conventional writing. Even with the results and conclusions obtained, it is important to carry out other studies as a whole in terms of literacy and literacy so that one can contribute even more to the scientific community.
\end{abstract}

Keywords: Literacy; Literacy; Learning difficulties.

Topic: Ensinos Multidisciplinares

Reviewed anonymously in the process of blind peer.
Received: $16 / 03 / 2020$

Approved: $14 / 05 / 2020$
Samira Bruno Diniz

Centro Universitário Vale do Salgado, Brasil

http://lattes.cnpq.br/0847499939430034

samiradiniz.va@gmail.com

Thais Faustino Bezerra

Universidade Regional do Cariri, Brasil

http://lattes.cnpq.br/4780592647217868

thaisfaustino00@gmail.com

José de Caldas Simões Neto (iD

Centro Universitário Dr. Leão Sampaio, Brasil

http://lattes.cnpq.br/0470733825644726

http://orcid.org/0000-0003-1036-2315

josedecaldas@leaosampaio.edu.br

\author{
Antoniel dos Santos Gomes Filho (D) \\ Centro Universitário Vale do Salgado, Brasil \\ http://lattes.cnpq.br/9563145614494252 \\ http://orcid.org/0000-0003-2230-4315 \\ antoniel.historiacomparada@gmail.com
}

Referencing this:

DINIZ, S. B.; BEZERRA, T. F.; SIMÕES NETO, J. C.; GOMES FILHO, A. S.. Alfabetização e letramento: um estudo de caso com um aprendente de escola pública. Educationis, v.8, n.2, p.49-55, 2020. DOI: http://doi.org/10.6008/CBPC2318-3047.2020.002.0007 


\section{INTRODUÇÃO}

O termo letramento pode ser considerado atual no campo da educação brasileira, onde foi usado inicialmente com uma abordagem antropológica, sendo que as práticas de leitura e escrita só começaram a ser pesquisadas a partir da década de 70.

[...] O termo letramento designa práticas de leitura e escrita, esse termo tem sido utilizado atualmente por alguns estudiosos para designar o processo de desenvolvimento das habilidades de leitura e de escrita nas práticas sociais e profissionais, já o termo alfabetização, sempre foi entendido de uma forma restrita como aprendizagem do sistema da escrita.

A leitura é parte integrante do processo de alfabetização e letramento da criança, pelo qual deve ser visto com um olhar amplo e não apenas como interpretações de formas. Através da leitura é possível ter uma compreensão eficaz do mundo em que se vive, sendo parte fundamental para a formação de um indivíduo no mundo atual.

Segundo Infante (2000) a leitura "[...] é o meio de que dispomos para adquirir informações e desenvolver reflexões críticas sobre a realidade". O que torna a leitura algo crucial para a aprendizagem do ser humano, pois é através dela que se pode enriquecer o vocabulário, obter conhecimento, dinamizar o raciocínio e a interpretação.

É na infância que se faz necessária a aquisição da leitura, principalmente nas séries iniciais do ensino fundamental I, já que a partir de uma base bem estruturada, o aprendente irá se desenvolver de forma mais integral. Para isso se faz necessário que o estudante possa sentir gosto pelos textos, sendo esses literários, informativos ou que possuam algum valor que possa agregar a sua aprendizagem. De acordo com a concepção piagetiana, "[...] o desenvolvimento ocorre no sentido de o sujeito adquirir uma determinada visão do mundo que o cerca, que lhe permita um estado de adaptação e de equilíbrio em relação às situações às quais está continuamente exposto" (RAPPAPORT, 1981).

Outro aspecto de suma importância é a escrita onde, segundo Ferreiro et al. (1999), "[...] a escrita é uma forma de representar aquilo que é funcionalmente significativo, estabelecendo um sistema de regras próprias". Sendo dividia em cinco níveis de escrita, que segundo a psicogênese da língua escrita são os seguintes: nível pré-silábico, silábico, silábico-alfabético, alfabético e ortográfico. Níveis esses que possibilitam compreender a criança no seu processo de aquisição da escrita.

Quando a criança ingressa na escola já traz consigo muitos conhecimentos, apesar de que algumas delas terem um conhecimento mais avançado devido o meio em que vive, pois tem contato com materiais escritos, que o mundo oferece o que acaba caracterizando uma abordagem pedagógica construtivista. Segundo Ferreiro et al. (1999) "[...] a criança não pode ser limitada, pois ela tem conhecimentos linguísticos superiores ao que imaginamos e a grande parte das crianças, desde pequenas, tem contato com a linguagem escrita através de livros, jornais, embalagens, placas, etc.".

Toda criança começa a construir seu conhecimento sobre a linguagem muito antes de frequentar a escola, assim é necessário oferecer uma maior gama de situações para que elas leiam e escrevam da forma delas. No início do processo as crianças sempre terão dificuldade e necessitarão de uma mediação, onde 
aparece o papel do professor, mais logo ganharão confiança e passarão a ler e a escrever.

Para se iniciar um processo de alfabetização de uma criança, o professor inicialmente precisa escolher qual método ele vai trabalhar, onde esse método deve levar em consideração a realidade em que o aprendente vive, sempre levando em apreço a forma lúdica e criativa. Não existe uma receita pronta para alfabetizar uma criança, pois cada criança diferisse uma da outra na questão da aprendizagem. 0 método aplicado com uma criança pode não ter o mesmo resultado com outra, já que a criança traz diversas concepções com ela através de sua realidade.

É necessário escolher um método, mesmo sabendo que não existe um método melhor que o outro, nada melhor do que aproveitar o processo de alfabetização inicial onde os alunos estão repletos de curiosidade e disposição para aprender o novo, onde se deve estimular a aproximação com a leitura e escrita.

Pode-se utilizar dos métodos sintéticos que partem da soletração para à consciência fonológica, onde a alfabetização através desse método parte de pequenas palavras e durante esse processo o professor pode escolher se vai fazer uso de cartilhas ou não. Em relação a esse método, Cagliari (1998) afirma que: “[...] partia-se do alfabeto para soletração e silabação, seguindo uma ordem hierárquica crescente de dificuldades, desde a letra até o texto".

Outro método de alfabetização é conhecido como analíticos ou globais. Sua aplicação visa alfabetizar a criança a partir de histórias ou orações. Esse método de alfabetização é muito importante, pois, ensinando a criança a ler e escrever a partir de histórias, ela está estimulando o aluno a criar gosto pela leitura. Este é um dos pontos positivos para a aplicação desse método. $\mathrm{O}$ objetivo da presente pesquisa foi relatar o caso de aprendente acerca da alfabetização e letramento do mesmo.

\section{METODOLOGIA}

A presente pesquisa trata-se de um estudo de caso com um aprendente de escola pública de ensino. O aprendente sexo masculino tem 6 anos de idade, cursa o primeiro ano do ensino fundamental na Escola de Ensino Infantil. Para a coleta dos dados foram desenvolvidas 10 sessões psicopedagógicos, sendo 5 sessões de diagnóstico e 5 sessões de intervenção, cada sessão teve duração de 50 minutos, e foram realizadas semanalmente dentro de um período de 3 meses. Foram aplicados 9 (nove) testes durante as sessões a fim de avaliar os aspectos cognitivos, pedagógicos, afetivos e psicomotores (Tabela 1).

Tabela 1: Objetivos dos Teste Desenvolvidos na Pesquisa.

\begin{tabular}{|l|}
\hline TESTES e OBJETIVOS \\
\hline EOCA: criar vínculos com o aprendente. \\
\hline Par educativo: investigar o vínculo com a aprendizagem. \\
\hline Dia do aniversário: investigar os vínculos familiares. \\
\hline Teste de Audibilização: contribuir para o diagnóstico dos distúrbios da língua escrita \\
\hline Discriminação Visual - forma: percepção visual, análise e síntese. \\
\hline Discriminação Visual - comprimento: noção de comprimento, organização, memória visual. \\
\hline Discriminação Visual - tamanho: déficits perceptivos, organização espacial. \\
\hline Letra Cursiva: verificar o traçado, o tônus, sincinesias e habilidades perceptivas-motoras. \\
\hline 4 Palavras e uma frase: perceber o nível de escrita das crianças. \\
\hline Função Analítica Sintética: capacidade de análise e síntese, qualidade na escrita. \\
\hline $\begin{array}{l}\text { Testes Pedagógicos - Linguagem e matemática: consiste em investigar o nível de aprendizagem e detectar as dificuldades de } \\
\text { aprendizagem. }\end{array}$ \\
\hline
\end{tabular}


Os procedimentos metodológicos da presente pesquisa se constituíram dentro dos padrões éticos legais referentes à pesquisa com seres humanos da resolução 446/12. A aceitação na participação da pesquisa foi permitida mediante a assinatura de um Termo de Consentimento Livre e Esclarecida (TCLE), assinada pelo responsável da criança. Mediante essa assinatura foi declarado a aceitação de forma voluntária para participar da referida pesquisa e do estudo, tendo o direito de retirar-se da pesquisa quando achar conveniente.

\section{Perfil do Aprendente}

$\mathrm{O}$ aprendente ' $\mathrm{V}$ ' do sexo masculino tem 6 anos de idade, cursa o primeiro ano do ensino fundamental na Escola de Ensino Infantil e Fundamental Iracy Bezerra de Morais, no turno matutino. Foi encaminhado pela professora juntamente com a avó do mesmo.

\section{Queixa}

Ao início do processo de diagnóstico psicopedagógico estava cursando o 1 o ano do ensino fundamental I, em uma escola da rede pública municipal. Sua maior dificuldade apresentada pela escola é, sobretudo, em leitura e escrita, por não conseguir acompanhar a turma no desenvolvimento das atividades que exigem o aprofundamento das mesmas. $\mathrm{O}$ aprendente realiza as tarefas, copia as atividades que a professora escreve no quadro, mas não sabe ler e escrever e conhece pouquíssimas letras.

\section{Anamnese}

$\mathrm{O}$ aprendente ' $\mathrm{V}$ ', sexo masculino, nascido no dia 29 de janeiro de 2014 , atualmente cursa o $1^{\circ}$ ano do ensino fundamental na Escola Iracy Bezerra de Morais. A entrevista de anamnese foi realizada com a avó materna do aprendente, pois ' $V$ ' mora na casa da mesma, sem a mãe desde os quatro anos de idade. Durante a entrevista foram feitas perguntas sobre as condições socioeconômicas da família do avaliando, a gestação, saúde, hábitos, desenvolvimento emocional, desenvolvimento psicomotor, cognitivo, da linguagem, social, a vida escolar e outros. A avó respondeu às perguntas que estavam no roteiro e a outras que surgiram no decorrer da entrevista, que foi realizada em uma sala reservada pela diretora da escola para a concretização das sessões.

Segundo informações colhidas, o aprendente é fruto de uma gestação indesejada, onde sua mãe a descobriu aos 15 anos de idade. Devido às circunstâncias e a juventude, a mãe realizou diversas tentativas abortivas através do uso de medicamentos, ingestão de bebidas alcoólicas, além de compressão do feto através do uso de roupas apertadas, isso teve como reflexo o diagnóstico de gravidez de risco, ocasionando ao final da gestação um processo de pré-eclâmpsia. Assim, ' $V$ ' nasceu prematuro (7 meses), necessitando permanecer na incubadora durante dois meses.

A avó da criança relata que a mãe sofreu de depressão pós-parto e que não chegou a amamentá-lo. Ao sair do hospital, ' $V$ ' passou a morar com a mãe na residência da avó materna, juntamente com mais cinco parentes. Quanto à paternidade, a mãe se recusa a revelar, a entrevistada relatou que a jovem já compareceu 
diversas vezes ao fórum da cidade para informar o paradeiro do pai da criança, porém a senhora não sabe informar se foi revelado. A certidão de nascimento de ' $V$ ' ainda consta pai ignorado.

Aos dois anos de idade, o aprendente passou a morar com sua mãe, seus dois irmãos mais novos (A e B) e o padrasto (pai de B e que é pai do genitor de A). Aos quatro anos ' $V$ ' passou a sofrer agressão física por parte de sua mãe, advindo a residir novamente com a sua avó materna, com quem vive atualmente. A avó relata que ' $V$ ' é uma criança muito frágil, que fica resfriado com muita facilidade e que sofre com problemas respiratórios. A senhora contou que antes de ' $V$ ' voltar a morar com ela foi jogado contra a parede por sua mãe o que ocasionou a ida ao hospital, pois a criança teria desmaiado por causa da forte pancada. Para melhor entendimento segue o organograma abaixo.

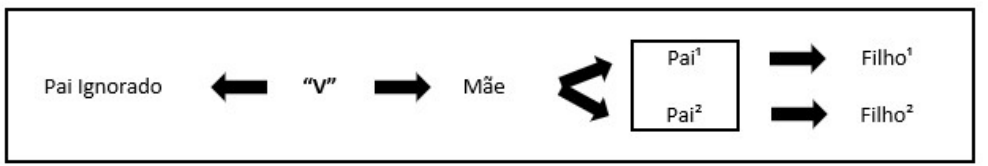

Figura 1: Composição Familiar do Aprendente. Nota: Pai ${ }^{2}$ é genitor do Pai ${ }^{1}$

O aprendente, dificilmente realiza visitas a sua mãe e aos seus irmãos, estabelecendo uma relação distante com a mesma. Mesmo com esses fatores a criança esboça um grande desejo de morar com sua genitora, já que a avó materna sofre de depressão, necessitando ingerir medicamentos controlados. Apesar da depressão, ela diz impor regras e normas de conduta, o que não é muito bem assimilado pela criança.

O aprendente é uma criança que não gosta muito de falar, seu tom de voz é baixo e apressado. Não olha no olho e quando é interrogado fica inquieto e diz sentir um incômodo na parte frontal da cabeça. Nesta análise foi possível perceber que o aprendente vive uma situação familiar traumática, pois apesar do esforço da avó em lhe agradar, o desejo da criança é ser aceito pela mãe e assim manter um relacionamento de afetividade com a mesma e com seus irmãos.

\section{Hipótese Diagnóstica}

Durante a avaliação diagnóstica foram feitas as sessões da E.O.C.A, avaliações relacionadas a desenhos e anamnese do paciente (com a avó), quando foi possível conhecer um pouco sobre sua história de vida e atividades ligadas à leitura e escrita, bem como às questões de raciocínio lógico-matemático, desenhos e expressões plásticas. Tudo, visando diagnosticar os aspectos sócio-afetivos associados à aprendizagem (interesses, autoestima, desejos e desenvolvimento social).

Diante disso, a hipótese levantada durante as sessões diagnósticas considera que a criança se encontra bloqueada por problemas emocionais, carregada de vínculos negativos que, consequentemente, estão interferindo negativamente na sua atenção para aprendizagem, desautorizando-o de ser mais criativo e de construir sua autoria de pensamento.

\section{Proposta de Intervenção}

Partindo das observações colhidas nas sessões diagnósticas, foi possível perceber que o aprendente não apresenta deficiências no que diz respeito à estrutura, comportamental e psicológica. Podendo assim 
dizer que ' $V$ ' apresenta uma grande carência emocional, o que reflete no seu aprendizado, tendo ainda um leve déficit cognitivo. Percebendo essa ausência de atenção e carinho, foi possível promover uma intervenção psicopedagógico lúdica e prazerosa, onde o aprendente não apresentou dificuldades em realizar as atividades propostas.

A maior dificuldade de ' $V$ ' se caracterizou na decodificação e assimilação das letras e sílabas, pois, segundo o mesmo, não conseguia lembrar os sons. Portanto, acredita-se ser necessário o encaminhamento deste aos seguintes especialistas: Ao Psicopedagogo para iniciar atendimento clínico; Ao Fonoaudiólogo para avaliação da consciência fonológica; Ao Neurologista para avaliação médica referente à sua prematuridade; Ao Psicólogo para tratamento psicoterápico familiar; Assistente social - encaminhar ao Centro de Referência da Assistência Social do município e o profissional avaliar a estrutura familiar em nível social e econômico.

\section{RESULTADOS E DISCUSSÃO}

Do ponto de vista afetivo demonstra condições inadequadas de relacionamento: o caso do aprendente vem ilustrar a problemática nas relações familiares observado nas provas projetivas onde os vínculos com o aprender são negativos, uma vez que as pessoas não interagem entre si, fazendo as coisas de forma isolada. Embora a avó revele afetividade ela mantém o neto muito independente, deixando-o agir de acordo com as suas vontades. Essa conduta afeta seu emocional contribuindo para que ele apresente dificuldade em lidar com o afeto e a imposição de limites. Ele apresenta um comportamento de alto grau de ansiedade, considerando que a situação no ambiente familiar impõe a ele restrições quanto ao fortalecimento das relações vinculares e uma comunicação truncada. Ainda foi observado em relação à ausência do pai e omissão da figura dos irmãos, pois hesita em falar deles, medo de expressar seus sentimentos, demonstra fragilidade e rejeição quando se trata em falar da família.

No cognitivo demonstra falta de envolvimento com o objeto de aprendizagem e com o conhecimento do transmissor. Seu nível pedagógico e criativo está abaixo de sua escolaridade e de sua faixa etária, encontra-se no período silábico sem valor sonoro, pois ele tem consciência que existe relação entre a fala e a escrita, porém não identifica os sons das letras, utilizando os símbolos gráficos de forma aleatória sem corresponder à escrita convencional.

Suas produções correspondem ao nível pré-operatório, onde é nesta fase que surge, na criança, a capacidade de substituir um objeto ou acontecimento por uma representação, esta substituição é possível, graças à função simbólica. Possui alto nível de atenção, dificuldade na concentração, é muito tímido, e tem um comportamento muito apreensivo, necessita de muita compreensão. É muito organizado, explora todo material disponibilizado, porém prefere usar o material já conhecido.

Sobre o aspecto pedagógico apresenta uma modalidade de aprendizagem hipoassimilativa, ou seja, toma pouca iniciativa, e precisa ser conduzido nas suas produções, bem como necessita de incentivo constante no trabalho que realiza. Nesta sintomatização ocorre uma assimilação precária, o que resulta na pobreza do contato com o objeto, de modo a não o transformar, não o assimilar de todo, apenas acomodálo. A acomodação consiste em adaptar-se para que ocorra a internalização. A sintomatização da acomodação 
pode se dar pela resistência em acomodar, ou seja, em uma dificuldade de internalizar os objetos (FERNÁNDEZ, 1991).

A análise de dados obtidos durantes as atividades realizadas revelam que ' $V$ ' apresenta baixo impulso epistemofílico para o conhecimento, isso significa dizer que possui os esquemas de pensamento para a aprendizagem, mas os utiliza parcialmente por falta de vinculação. Quanto à organização, possui mecanismos antecipatórios, utilizando a assimilação e a acomodação quando deseja. Não cria algo novo, mas recria a partir de algo assimilado. Assim, não há predomínio da acomodação sobre assimilação, desconcentrando-se do objeto de aprendizagem.

\section{CONCLUSÕES}

O presente estudo buscou investigar as dificuldades de aprendizagem de um aluno da rede municipal de ensino de Várzea Alegre/CE, regulamente matriculado no ensino fundamental inicial, utilizou-se na pesquisa o método de estudo de caso, onde segundo Araújo et al. (2008) "o estudo de caso trata-se de uma abordagem metodológica de investigação especialmente adequada quando procuramos compreender, explorar ou descrever acontecimentos e contextos complexos, nos quais estão simultaneamente envolvidos diversos fatores".

Concluir-se, com esta pesquisa, que o aprendente aparenta ter problemas de ordem afetivos, cognitivos e pedagógicos, possivelmente devido a prematuridade do seu nascimento e a confusão familiar encontrada dentro de sua residência. A partir dos resultados encontrados, podemos concluir que o mesmo necessita de um acompanhamento multidisciplinar através de uma equipe de Neurologista, Psicólogo, Assistente Social e Psicopedagogo, visando contribuir para resolução adequada das situações evidenciadas na pesquisa. Mesmo com os resultados e as conclusões obtidas, torna-se importante realizar outros estudos em seu conjunto, buscando incorporar novas pesquisas em torno da alfabetização e letramento.

\section{REFERÊNCIAS}

ARAÚJO, C.; PINTO, E. M. F.; LOPES, J.; NOGUEIRA, L.; PINTO R.. Estudo de Caso: Métodos de Investigação em Educação. Dissertação (Mestrado em Educação) - Universidade do Minho, 2008.

CAGLIARI, L. C.. Alfabetizando sem o Bá-Bé-Bi-Bó-Bu: Pensamento e Ação no Magistério. São Paulo: Scipione, 1998.

FERNÁNDEZ, A.. A Inteligência Aprisionada. Porto Alegre: ArtMed, 1991.
FERREIRO, E.; TEBEROSKY, A.. Psicogênese da Língua Escrita. Porto Alegre: ArtMed, 1999.

INFANTE, U.. Texto: Leitura e escritas. São Paulo: Scipione, 2000 .

RAPPAPORT, C. R.. A idade pré-escolar. São Paulo: Pedagógica e Universitária Ltda., 1981.

A CBPC - Companhia Brasileira de Produção Científica (CNPJ: 11.221.422/0001-03) detém os direitos materiais desta publicação. Os direitos referem-se à publicação do trabalho em qualquer parte do mundo, incluindo os direitos às renovações, expansões e disseminações da contribuição, bem como outros direitos subsidiários. Todos os trabalhos publicados eletronicamente poderão posteriormente ser publicados em coletâneas impressas sob coordenação da Sustenere Publishing, da Companhia Brasileira de Produção Científica e seus parceiros autorizados. Os (as) autores (as) preservam os direitos autorais, mas não têm permissão para a publicação da contribuição em outro meio, impresso ou digital, em português ou em tradução. 